\title{
Modified Tournament Model Based on Perceived Wage
}

\author{
Qiang Guo ${ }^{1 *}$, Chengyu Jiang ${ }^{2}$ \\ ${ }^{1}$ Management School, Northwest Polytechnical University, Shaanxi, China; ${ }^{2}$ Northwest Polytechnical University, Shaanxi, China. \\ Email: "guoqianghainan@gmail.com
}

Received July 26 ${ }^{\text {th }}$, 2012; revised August 27 ${ }^{\text {th }}$ 2012; accepted September $28^{\text {th }}$, 2012

\begin{abstract}
In this paper, we combine the relative satisfaction and relative deprivation stemmed from wage comparison to form the relative perception as the integrated influence factor on the individual's utility function, which is the most different point from the former tournament theory studies. We introduce the relative perception into the tournament model and then analyze the Nash Equilibrium of the output competition game based on this modified model. Consequently, some new findings are obtained. Firstly, we find the relative perception could affect the utility of workers as similar as what the wage dispersion does. What's more, the income-utility sensitivity can also affect the decision of workers to choose the effort level. According to what is found in this study, the subjective perception should be paid enough attention to since it could affect the worker both in utility and consequent action. Besides, the wage policy should design properly and the differences in subjective sensitivity to relative perception or the proportion of income or perception among workers should be taken into account when the wage strategy is made.
\end{abstract}

Keywords: Relative Deprivation; Relative Satisfaction; Relative Perception; Tournament Model; Yitzhaki Index

\section{Introduction}

Undoubtedly, getting paid is an essential motivation for people to work. Meanwhile, income is always regarded as an indicator of their achievement and recognition (Goodman, 1974) [1]. In the reign of neoclassical economics, the equilibrium of free market achieves as wage equals the value of marginal product (Mankiw, 1995) [2]. However, Doeringer and Piore (1971) [3] argued that there exist obvious differences between the external and internal labor market. Jensen and Meckling (1976) [4] further extended the conception of wage allocation in the internal labor market properly by defining the contract between the principal and agent under the condition that ownership and management are separated. To prevent the moral hazard problems, by employing the conception of relative performance evaluation, Lazear and Rosen (1981) [5] proposed the tournament theory which presents a hierarchical wage structure and a tournament-like way for workers to achieve some preset wage level. The rational result obtained from this theory is that workers will make more effort when they are faced with larger wage dispersion.

No matter what differences exist among the traditional theories on pay-performance relationship, they are all assumed that the only thing workers care is their own wage. In other words, the subjective perception stemmed

*Corresponding author. from income comparison just like the air in the vacuum. Unfortunately, more and more studies showed that people actually care about others' situation, which really affect their own benefit. Crosby $(1976,1984)[6,7]$ and Martin (1981) [8] stated that this kind of perception tends to affect the workers' productivity devastatingly by causing stress symptoms, negative attitudes, undesirable work behaviors and so on. Consistently, Sweeney et al. (1990) [9] imposed that this perception is associated with pay dissatisfaction.

In this paper, we manage to incorporate the subjective perception caused by the income comparison into the original tournament model in order to show whether the workers strategies and firm performance will be influenced. The rest of the paper is organized as follows: Part II is literature review, Part III is modeling, Part IV is analysis and findings and Part V is implication and conclusion.

\section{Literature Review}

The term of relative deprivation originated in a post-war psychological study on the US army (Stouffer et al., 1949) [10] and the theory of relative deprivation was articulated and formalized in Runciman (1966) [11]. In this seminal work, an individual's feeling of deprivation was illustrated by an example of promotion and four preconditions are defined for an individual to obtain this sort of feeling, which are 1) he does not have $\mathrm{X}, 2$ ) he 
sees some other person or persons as having $X, 3$ ) he wants $X$, and 4) he sees it as feasible that he should have $X$. In another nobly work, five preconditions are noted (Crosby, 1976) [6], which are 1) they want some object $X, 2$ ) they feel entitled to $X, 3$ ) they perceive that someone else possesses $X, 4$ ) they think it feasible to attain $X$, and 5) they refuse personal responsibility for their current failure to possess $\mathrm{X}$ themselves. After simplified in Crosby (1984) [7], two foundational preconditions are suggested, namely, wanting $\mathrm{X}$ and deserving $X$. Since then, this theory providing insights into the subjective well-being has attracted much attention in many fields.

Beyond psychology view, Sen (1976) [12] firstly introduced the income distribution into the study on relative deprivation. What's more specifically, one salient index in the context of relative deprivation depicting the relative-weighted income from all the persons in the better-off condition came forth in Yitzhaki (1979) [13]. This Yitzhaki index defines the relative deprivation as the sum of the differentials between some individual income and all upper-ranked incomes, which is usually utilized as the measurement for relative deprivation. After that, Martin (1981) [8] proposed that the relative deprivation stems from a comparison on rewards among persons or groups and finally introduced the conception of relative deprivation into the work and organization study.

Relative deprivation always focuses on the negative cognition referring to the perception of disparity. However, another sort of feeling can also be obtained from the income comparison when the individual has a better salary. Contrast to the relative deprivation, this feeling is positive and consequently can be defined as relative satisfaction. Such as what Moyes (2007) [14] pointed out, an individual could find some comfort when the poorer persons are chosen as the reference group. By reconstructing it, Hey and Lambert (1980) [15] divided the Yitzhaki index into the mean income and the satisfaction index. Stark and Yitzhaki (1988) [16] claimed that the satisfaction originates from having $\mathrm{X}$ and the deprivation from having no more than $\mathrm{X}$ and assumed that the satisfaction and the deprivation functions are complement each other and the sum of them is mean income. Chakravarty (1997) [17] represented the notion of satisfaction as the complement of the deprivation to the mean income, which is in lines with Hey and Lambert (1980) [15] and Stark and Yitzhaki (1988) [16]. In addition, Ebert and Moyes (2000) [18] found a dual relationship between the index of deprivation and the one reflecting satisfaction. All in all, people always obtain the perception from the income comparison, positive, negative or both. Generally, we could get an aggregated perception (defined as relative perception in this paper) by choosing the different referent groups at the same time when we are among the richer ones and poorer ones.

It is obvious that the subjective perception does matter to the well-beings of people according to the theory of relative deprivation. However, the original tournament model doesn't take it into account and assumes the individual's utility can be affected only by her own income. In this paper, what we are interested in is whether the wage dispersion can also work well as an incentive mechanism to improve workers' output when the relative perception exists. In addition, how much relative perception affects the workers' effort is also an issue we would like to explore.

\section{Modeling}

Following Lazear and Rosen (1981)[5], we assume two identical workers $i$ and $j$ are employed in one representative firm $X$ and all of them are risk-neutral. The output of worker $k$ is $q_{k}\left(e_{k}, \varepsilon_{k}\right)=e_{k}+\varepsilon_{k}$, for $k=i, j$, where $e_{k}$ and $\varepsilon_{k}$ denote the effort and random influence on the output of worker $k$. The firm's output is the sum of workers' outputs which can be calculated by the equation $Q=q_{i}\left(e_{i}, \varepsilon_{i}\right)+q_{j}\left(e_{j}, \varepsilon_{j}\right)$. Given the hierarchical wage structure formed by high-level $W_{H}$ and low-level $W_{L}$ is exogenous, we assume the winner in the output competition obtains the higher wage $W_{H}$ and the loser gets the lower one $W_{L}$. Based on the definition, $P_{i}$, the probability for worker $i$ to achieve the higher wage, is

$$
\begin{aligned}
P_{i} & =\operatorname{prob}\left(q_{i}>q_{j}\right)=\operatorname{prob}\left(\left(e_{i}+\varepsilon_{i}\right)>\left(e_{j}+\varepsilon_{j}\right)\right) \\
& =\operatorname{prob}\left(\left(e_{i}-e_{j}\right)>\left(\varepsilon_{j}-\varepsilon_{i}\right)\right) \\
& =\operatorname{prob}\left(\left(e_{i}-e_{j}\right)>\xi\right)=\int_{-\infty}^{e_{i}-e_{j}} g(\xi) \mathrm{d} \xi=G\left(e_{i}-e_{j}\right)
\end{aligned}
$$

where $\xi=\varepsilon_{j}-\varepsilon_{i}$ and $\xi \sim g(\xi) . G(\xi)$ is the cumulative distribution function of $\xi$ and $E(\xi)=0$.

In line with Clark and Oswald (1998) [19], we assume individual's utility is impacted by three items, namely, the effort to work, income for the work and perception originated from comparison of the income with the relevant group. Following the most literature, we consider the effort to work as a sort of disutility which means the effort will be negatively related to the utility. We denote this kind influence on worker $k$ as $u_{k}^{-}\left(e_{k}\right)$ and assume $u_{k}^{-}\left(e_{k}\right)^{\prime}>0$ and $u_{k}^{-}\left(e_{k}\right)^{\prime \prime}>0$. Contrarily, income is always positive to individual's utility, $u_{k}^{+}\left(W_{k}\right)$ is denoted to present this kind influence on worker $k$. Besides, the comparison of income will affect the individual's utility when the subjective perception is taken into account, which is denoted as $v_{k}\left(W_{k}-W_{\bar{k}}\right)$ in this paper. As mentioned above, two components devote to contributing the perception from comparison, the relative deprivation component discussed in many former studies and 
the relative satisfaction component discussed in Spilimbergo and Ubeda (2004) [20] where the social satisfaction is incorporated into the utility function. Because the perception obtained from different relevant groups is obviously different, $v_{k}\left(W_{k}-W_{\bar{k}}\right)$ should be the aggregated effect on the utility of worker $k$. So we define

$$
v_{k}\left(W_{k}-W_{\bar{k}}\right)=\alpha \max \left\{0, W_{k}-W_{\bar{k}}\right\}+\beta \min \left\{0, W_{k}-W_{\bar{k}}\right\},
$$

where $\alpha$ is the sensitivity of relative satisfaction to the wage dispersion and $\beta$ is the sensitivity of relative deprivation to the wage dispersion. Similar with Carlsson and Qin (2010) [21], we adopt an additive comparison utility function, where the relative deprivation is depicted as the difference of the wage gap between the individual and the richer ones. Enlightened by Johansson-Stenman et al. (2002) [22], we denote the income-utility sensitivity as $\lambda$ and the perception-utility sensitivity as $1-\lambda$ consequently. And the utility function of worker $k$ could be expressed as follows.

$$
U_{k}=-u_{k}^{-}\left(e_{k}\right)+\lambda u_{k}^{+}\left(W_{k}\right)+(1-\lambda) v_{k}\left(W_{k}-W_{\bar{k}}\right) .
$$

Since the probability for worker $i$ to win the higher wage is $P_{i}$, the expected utility function in Von Neumann-Morgenstern form could be employed to describe the decision preference of workers (Neumann and Morgenstern, 1944) [23] and the function is as follows.

$$
\begin{aligned}
E U_{i} & =E\left[-u_{i}^{-}\left(e_{i}\right)+\lambda u_{i}^{+}\left(W_{i}\right)+(1-\lambda) v_{i}\left(W_{i}-W_{\bar{i}}\right)\right] \\
& =P_{i}\left[-u_{i}^{-}\left(e_{i}\right)+\lambda W_{X}^{H}+(1-\lambda) \alpha\left(W_{H}-W_{L}\right)\right] \\
& +\left(1-P_{i}\right)\left[-u_{i}^{-}\left(e_{i}\right)+\lambda W_{L}+(1-\lambda) \beta\left(W_{L}-W_{H}\right)\right] \\
& =\left\{[(1-\lambda)(\alpha+\beta)+\lambda] P_{i}-\beta(1-\lambda)\right\} \\
& \cdot\left(W_{H}-W_{L}\right)+\lambda W_{L}-u_{i}^{-}\left(e_{i}\right)
\end{aligned}
$$

Rationally and strategically, workers choose the best effort level to maximize their own expected utility. The first and the second order condition for this effort-making decision problem are as follows.

F.O.C.

$$
\begin{aligned}
& {[(1-\lambda)(\alpha+\beta)+\lambda]\left(W_{H}-W_{L}\right) \partial P_{i} / \partial e_{i}-\partial u_{i}^{-}\left(e_{i}\right) / \partial e_{i}=0} \\
& \quad \text { S.O.C. } \\
& {[(1-\lambda)(\alpha+\beta)+\lambda]\left(W_{H}-W_{L}\right) \partial^{2} P_{i} / \partial e_{i}^{2}-\partial^{2} u_{i}^{-}\left(e_{i}\right) / \partial e_{i}^{2}} \\
& <0
\end{aligned}
$$

Given the competitor's action, the best response function for worker $i$ is

$$
[(1-\lambda)(\alpha+\beta)+\lambda]\left(W_{H}-W_{L}\right) \partial P_{i} / \partial e_{i}=\partial u_{i}^{-}\left(e_{i}\right) / \partial e_{i}
$$

Since $\partial P_{i} / \partial e_{i}=\partial G\left(e_{i}-e_{j}\right) / \partial e_{i}=g\left(e_{i}-e_{j}\right)$, the equation above can be rewritten as

$$
\begin{aligned}
& {[(1-\lambda)(\alpha+\beta)+\lambda]\left(W_{H}-W_{L}\right) g\left(e_{i}-e_{j}\right)} \\
& =\partial u_{i}^{-}\left(e_{i}\right) / \partial e_{i}
\end{aligned}
$$

Given the competitor's action, the best response function for worker $j$ is

$$
\begin{aligned}
& {[(1-\lambda)(\alpha+\beta)+\lambda]\left(W_{H}-W_{L}\right) \partial P_{j} / \partial e_{j}} \\
& =\partial u_{j}^{-}\left(e_{j}\right) / \partial e_{j}
\end{aligned}
$$

Since

$$
\partial P_{j} / \partial e_{j}=\partial G\left(e_{j}-e_{i}\right) / \partial e_{j}=g\left(e_{j}-e_{i}\right),
$$

the equation above can be rewritten as

$$
\begin{aligned}
& {[(1-\lambda)(\alpha+\beta)+\lambda]\left(W_{H}-W_{L}\right) g\left(e_{j}-e_{i}\right)} \\
& =\partial u_{j}^{-}\left(e_{j}\right) / \partial e_{j}
\end{aligned}
$$

Because the best functions of worker $i$ and $j$ are symmetric and these two workers are identical as assumed, the best solutions for them should be same such as $e_{i}^{*}=e_{j}^{*}$. As a result,

$$
\begin{aligned}
& {[(1-\lambda)(\alpha+\beta)+\lambda]\left(W_{H}-W_{L}\right) g(0)} \\
& =\partial u_{k}^{-}\left(e_{k}\right) / \partial e_{k}
\end{aligned}
$$

should be the Nash Equilibrium for the worker $k$, where $k=i, j$.

\section{Analysis and Findings}

As Lazear and Rosen stated in the seminal work of tournament theory, a hierarchical wage structure with two different wage levels is preset and two workers compete for the higher wage via output. The main conclusion argues that wage dispersion and environment noise could affect the effort decision of workers. More effort will be exerted with the wage dispersion or the noise level. Comparing the original tournament model, we take the workers' subjective perception on the wage dispersion into account, which makes the model in this paper is different from the original one and help us to extend the existing knowledge in this field via the comparative static method. We find the effort level which the workers choose is affected by both the wage dispersion and the subjective perception in term of the income-utility sensitivity and the sensitivity of relative deprivation (satisfaction) to the wage dispersion. Some new findings in detail are followed.

Findings A. Given other conditions fixed, workers tend to make more effort with the wage dispersion (noise level) increasing, which is in line with the result obtained from the original tournament model.

Proof A. Given other condition fixed, $u_{k}^{-}\left(e_{k}\right)^{\prime}$ will increase with wage dispersion $\left(W_{H}-W_{L}\right)$ (or noise level $g(0)$ ) since 


$$
\begin{aligned}
& {[(1-\lambda)(\alpha+\beta)+\lambda]\left(W_{H}-W_{L}\right) g(0)} \\
& =u_{k}^{-}\left(e_{k}\right)^{\prime} .
\end{aligned}
$$

What's more, effort will increase with $u_{k}^{-}\left(e_{k}\right)^{\prime}$ because $u_{k}^{-}\left(e_{k}\right)^{\prime}>0$. Combining the deduction above, the conclusion can be obtained that effort will increase with wage dispersion (noise level).

Findings B. Given other conditions fixed, the sensitivity of relative satisfaction and deprivation will be positively related to the effort level of workers, which means increasing the sensitivity of relative satisfaction or deprivation will enhance the effort level. In other words, wage dispersion should be decreased to maintain the effort level when the sensitivity of relative satisfaction or deprivation increases, vice verse. This result shows that the relative satisfaction or deprivation could motivate the workers as similar as what the wage dispersion does.

Proof B: Given other conditions fixed,

$\partial[(1-\lambda)(\alpha+\beta)+\lambda] / \partial \alpha=1-\lambda>0$ because $\lambda<1$, which implicates $u_{k}^{-}\left(e_{k}\right)^{\prime}$ will increase with $\alpha$ according to the equation

$$
[(1-\lambda)(\alpha+\beta)+\lambda]\left(W_{H}-W_{L}\right) g(0)=u_{k}^{-}\left(e_{k}\right)^{\prime} .
$$

Since $u_{k}^{-}\left(e_{k}\right)^{\prime}>0$, effort will increase with $u_{k}^{-}\left(e_{k}\right)^{\prime}$ and consequently increase with the sensitivity of relative satisfaction. The effort level will increase with the sensitivity of relative deprivation could be proved in the similar way.

Findings $\boldsymbol{C}$. In case of $\alpha+\beta=1$, the subject perception will not affect the effort level, which is a very special case. Under this situation, all conclusions are the same with the ones from the original model.

Proof $C$ : The Nash Equilibrium is simplified to $\left(W_{H}-W_{L}\right) g(0)=\partial u_{k}^{-}\left(e_{k}\right) / \partial e_{k}$ which is the same with the result obtained from the original model when $\alpha+\beta=1$ and then $(1-\lambda)(\alpha+\beta)+\lambda=1$.

Findings $\boldsymbol{D}$. Given other conditions fixed, the income-utility sensitivity will be helpful to increase the effort level when $\alpha+\beta<1$. In other words, the effort level will increase with the income if the subjective perception of the wage disparity is less obvious. Under this situation, decreasing the wage disparity properly will maintain the effort level. Vice verse, the income-utility sensitivity will be negative to increase the effort level when $\alpha+\beta>1$ and other conditions are fixed, which means the effort level will decrease with the income increasing if the subjective perception of the wage disparity is more obvious. Under this situation, enlarging the wage disparity is the way to maintain the effort level of workers.

Proof D: If the worker's effort increases with $\lambda$, it implies $[(1-\lambda)(\alpha+\beta)+\lambda]$ is monotone increasing function. So, $\partial[(1-\lambda)(\alpha+\beta)+\lambda] / \partial \lambda>0$. In other words, $\alpha+\beta<1$. If the worker's effort increases with $\lambda$ decreasing, $[(1-\lambda)(\alpha+\beta)+\lambda]$ should be monotone decreasing, which means

$\partial[(1-\lambda)(\alpha+\beta)+\lambda] / \partial \lambda<0$. In other words, $\alpha+\beta>1$.

\section{Conclusions and Implication}

Considering the relative perception combined by the relative satisfaction and relative deprivation as one influence factor on the individual's utility function is the most different point from the former tournament theory studies. After we analyzing the Nash Equilibrium of this output competition game and implementing the comparative static studies, some new interesting findings are shown in front of us. First of all, the relative perception could affect the utility of workers and motivate the workers as similar as what the wage disparity does unless the sensitivity of relative satisfaction to the wage disparity and the sensitivity of relative deprivation to the wage disparity are complementary to 1 . What's more, the income-utility sensitivity being related to worker's utility implies the degree of importance of income for workers will influence the workers' effort-making decision. In detail, the income-utility sensitivity will be helpful to increase the effort level when the sum of the sensitivity of relative satisfaction and deprivation to the wage disparity is less than 1 , otherwise, the income-utility sensitivity will be negative to increase the effort level when the sum of the sensitivity of relative satisfaction and deprivation to the wage disparity is more than 1 . Last but not least, the enlarged wage gap can motivate workers to make more effort and the bigger noise from outside needs more compensation gap is also found in this study, which is in line with the results originated from the traditional tournament model.

According to what is found in this study, the subjective perception should be paid enough attention to since it could affect the worker both in utility and consequent action. Whether the influence is positive or negative is depend. More detailed, increasing the proportion of income influence will stimulate worker to make more effort when the workers is less sensitive to the perception of relative satisfaction or deprivation, vice verse. This finding implies that the wage policy should design carefully and the differences in subjective sensitivity to relative perception or the proportion of income and perception among workers should be taken into account when a proper wage strategy is made.

\section{REFERENCES}

[1] P. S. Goodman, “An Examination of Referents Used in 
the Evaluation of Pay," Organizational Behavior and Human Performance, Vol. 12, No. 2, 1974, pp. 170-195.

[2] N. G. Mankiw, "Principles of Economics," South-Western Publishing, Nashville, 1995. doi:10.1016/0030-5073(74)90045-2

[3] P. B. Doeringer and M. J. Piore, "Internal Labor Markets and Manpower Analysis,” M. E. Sharp, New York, 1971.

[4] M. C. Jensen and W. H. Meckling, "Theory of the Firm: Managerial Behavior, Agency Costs and Ownership Structure,” Journal of Financial Economics, Vol. 3, No. 4, 1976, pp. 305-360. doi:10.1016/0304-405X(76)90026-X

[5] E. P. Lazear and S. Rosen, "Rank-Order Tournaments as Optimum Labor Contracts," Journal of Political Economics, Vol. 89, No. 5, 1981, pp. 841-864. doi:10.1086/261010

[6] F. A. Crosby, "A Model of Egoistical Relative Deprivation,” Psychological Review, Vol. 83, No. 2, 1976, pp. 85-113. doi:10.1037/0033-295X.83.2.85

[7] F. A. Crosby, "Relative Deprivation in Organizational Settings,” In: B. M. Staw \& L. L. Cummings, Eds., Research in Organizational Behavior, JAI Press, Greenwich, 1984, pp. 51-93.

[8] I. Martin, "Relative deprivation: A Theory of Distributive Injustice for an Era of Shrinking Resources,” In: L. L. Cummings \& B. M. Staw, Eds., Research in Organizational Behavior, JAI Press, Greenwich, 1981, pp. 53-107.

[9] P. D. Sweeney, D. B. McFarlin and E. J. Inderrieden, "Using Relative Deprivation Theory to Explain Satisfaction with Income and Pay Level: A Multistudy Examination,” Academy of Management Journal, Vol. 33, No. 2, 1990, pp. 423-436. doi:10.2307/256332

[10] S. A. Stouffer, E. A. Suchman, L. C. DeVinney, S. A. Star and R. M. Williams Jr., "The American Soldier: Adjustment During Army Life,” Princeton University Press, Princeton, 1949.

[11] W. G. Runciman, "Relative Deprivation and Social Justice,” Routledge, London, 1966.

[12] A. K. Sen, "Poverty: An Ordinal Approach to Measurement,” Econometrica, Vol. 44, No. 2, 1976, pp. 219-231. doi:10.2307/1912718
[13] S. Yitzhaki, "Relative Deprivation and the Gini Coefficient,” The Quarterly Journal of Economics, Vol. 93, No. 2, 1979, pp. 321-324. doi:10.2307/1883197

[14] P. Moyes, “An Extended Gini Approach to Inequality Measurement," Journal of Economic Inequality, Vol. 5, No. 3, 2007, pp. 279-303. doi:10.1007/s10888-006-9051-7

[15] J. D. Hey and P. Lambert, "Relative Deprivation and the Gini Coefficient: Comment,” Quarterly Journal of Economics, Vol. 95, No. 3, 1980, pp. 567-573. doi:10.2307/1885094

[16] O. Stark and S. Yitzhaki, "Labour Migration as a Response to Relative Deprivation,” Journal of Population Economics, Vol. 1, 1988, pp. 57-70. doi:10.1007/BF00171510

[17] S. R. Chakravarty, "Relative Deprivation and Satisfaction Orderings,” Keio Economic Studies, Vol. 34, No. 2, 1997, pp. 17-32.

[18] U. Ebert and P. Moyes, "An Axiomatic Characterization of Yitzhaki's Index of Individual Deprivation," Economics Letters, Vol. 68, No. 3, 2000, pp. 263-270. doi:10.1016/S0165-1765(00)00248-2

[19] A. E. Clark and A. J. Oswald, "Comparison-Concave Utility and Following Behavior in Social and Economic Settings," Journal of Public Economics, Vol. 70, No. 1, 1998, pp. 133-155. doi:10.1016/S0047-2727(98)00064-4

[20] A. Spilimbergo and L. Ubeda, "A Model of Multiple Equilibria in Geographic Labor Mobility,” Journal of Development Economics, Vol. 73, No. 1, 2004, pp. 107-123.

[21] F. Carlsson and P. Qin, "It Is Better to Be the Head of a Chicken than the Tail of a Phoenix: Concern for Relative Standing in Rural China,” Journal of Socio-Economics, Vol. 39, No. 2, 2010, pp. 180-186. doi:10.1016/j.socec.2010.02.003

[22] O. Johansson-Stenman, F. Carlsson and D. Daruvala, "Measuring Future Grand-Parents’ Preferences for Equality and Relative Standing,” Economic Journal, Vol. 112, No. 479, 2002, pp. 362-383. doi:10.1111/1468-0297.00040

[23] J. von Neumann and O. Morgenstern, "Theory of Games and Economic Behavior,” 3rd Edition, Princeton University Press, Princeton, 1953. 